$09 ; 14$

\title{
Оптический эффект вращения плоскости поляризации света в ДНК-содержащих материалах
}

\author{
(C) Н.В. Каманина ${ }^{1,2}$, А.А. Каманин ${ }^{3}$, С.В. Лихоманова ${ }^{1}$ \\ ${ }^{1}$ АО „ГОИ им. С.И. Вавилова“, Санкт-Петербург, Россия \\ ${ }^{2}$ Санкт-Петербургский электротехнический университет „ЛЭТИ“, Санкт-Петербург, Россия \\ ${ }^{3}$ Первый Санкт-Петербургский государственный медицинский университет им. акад. И.П. Павлова, Санкт-Петербург, \\ Россия \\ E-mail: nvkamanina@mail.ru
}

Поступило в Редакцию 16 апреля 2018 г.

На примере водных растворов ДНК показано проявление эффекта вращения плоскости поляризации света (в сравнении с рядом красителей). Установлены численные значения угла вращения, существенно превышающие таковые для водных растворов красителей и сахара, традиционно используемых в сахариметрах и поляриметрах. Таким образом, выявлен и подтвержден еще один из оптических эффектов, реализуемых в области биоструктурирования оптических материалов.

DOI: 10.21883/PJTF.2019.03.47263.17333

В течение последних 20-25 лет довольно много научно-технических коллективов уделяло внимание изучению влияния биообъектов, например ДНК, на изменение структурных, проводниковых и химических свойств материалов [1-6]. В частности, изучалась возможность ДНК-структур проявлять свои ориентирующие особенности и выявлять особенности право- и левовращающего агента при рассмотрении жировых клеток, растворов, других матричных систем [7-10].

Однако до сих пор мало внимания уделено сравнительному анализу влияния ДНК на ряд оптических эффектов при изучении биоструктурированных систем, хотя естественно, что оптика эффективно создает основы новых перспективных нано- и биотехнологий.

При этом следует отметить, что биоструктурированные материалы по своим рефрактивным и спектральным параметрам вполне конкурентоспособны (в сравнении с наноструктурированными тонкопленочными, а тем более с объемными неорганическими кристаллами). С использованием схемы Z-сканирования [11] и четырехволнового смешения лазерных пучков $[12,13]$ были зарегистрированы высокие значения нелинейных параметров для систем с ДНК. На примере жидкокристаллических модельных матриц было продемонстрировано, что значения светоиндуцированного изменения показателя преломления, определяющие коэффициенты нелинейной рефракции и кубической нелинейной восприимчивости жидкокристаллических композитов с ДНК, сравнимы с проявляемыми при структурировании органических сопряженных матриц с фуллеренами и квантовыми точками. Дополнительно в работе [14] осуществлено ориентирование эритроцитов и ДНК.

Следует отметить, что изучение оптических эффектов в материалах занимает особое место в современном становлении инновационных технологий. С одной стороны, это связано с тем обстоятельством, что энергия фотона лежит в диапазоне электронных и колебательных переходов в веществе; следовательно, это позволяет использовать свет, а более конкретно именно лазерное излучение для получения уникальной информации о структурных и динамических свойствах материалов, проявлении новых и подтверждении классических эффектов в них. С другой стороны, существенно расширяется область применения новых разработок. Поэтому проводимое в настоящей работе исследование эффекта вращения плоскости поляризации света при прохождении последнего через системы с введенными биообъектами на основе ДНК в сравнении с традиционно используемыми для этих целей водными растворами сахара [15] своевременно.

Для проведения измерений угла вращения плоскости поляризации света в нано- и биосенсибилизированных органических матрицах была использована разработанная схема, аналогичная применяемой в сахариметрах и поляриметрах. Принцип работы и общая схема, применяемые для осуществления экспериментов по вращению плоскости поляризации света, показаны на рисунке, $a, b$.

Установка, показанная на рисунке, $b$, позволяет выявить и детально изучить тенденцию замены эффективных нанообъектов нетоксичными природно возобновляемыми биообъектами на примере проявления эффекта вращения плоскости поляризации света.

В таблице представлены данные по измеренным углам вращения плоскости поляризации света. Приведены значения указанного параметра для водных растворов с ДНК, а также для систем с водорастворимыми красителями. Структурные формулы и спектральные характеристики водорастворимых красителей, используемых для сравнения в данном эксперименте, приведены в [16].

В ходе эксперимента наблюдалось, что угол вращения плоскости поляризации света для ДНК-содержащих растворов в несколько раз превышает значение этого параметра, измеренное для других систем. Так, видно, что все изучаемые водные растворы красите- 
Углы вращения плоскости поляризации

\begin{tabular}{l|c|c|c}
\hline \multicolumn{1}{c|}{ Образец } & $\begin{array}{c}\text { Концентрация } \\
\text { сенсибилизатора, } \\
\text { wt.\% }\end{array}$ & $\begin{array}{c}\text { Угл вращения } \\
\text { плоскости } \\
\text { поляризации света, }\end{array}$ & $\begin{array}{c}\text { Литературная } \\
\text { ссылка }\end{array}$ \\
\hline $\begin{array}{l}\text { Водный раствор ДНК } \\
\text { Водорастворимый }\end{array}$ & 0.3 & $3-3.8$ & Наст. раб. \\
$\begin{array}{l}\text { краситель ENS-291 } \\
\text { Водорастворимый }\end{array}$ & 0.1 & 0.12 & {$[16]$} \\
$\begin{array}{l}\text { краситель ENS-295 } \\
\text { Водорастворимый } \\
\text { краситель ENS-102 }\end{array}$ & 0.1 & 0.2 & {$[16]$} \\
\end{tabular}
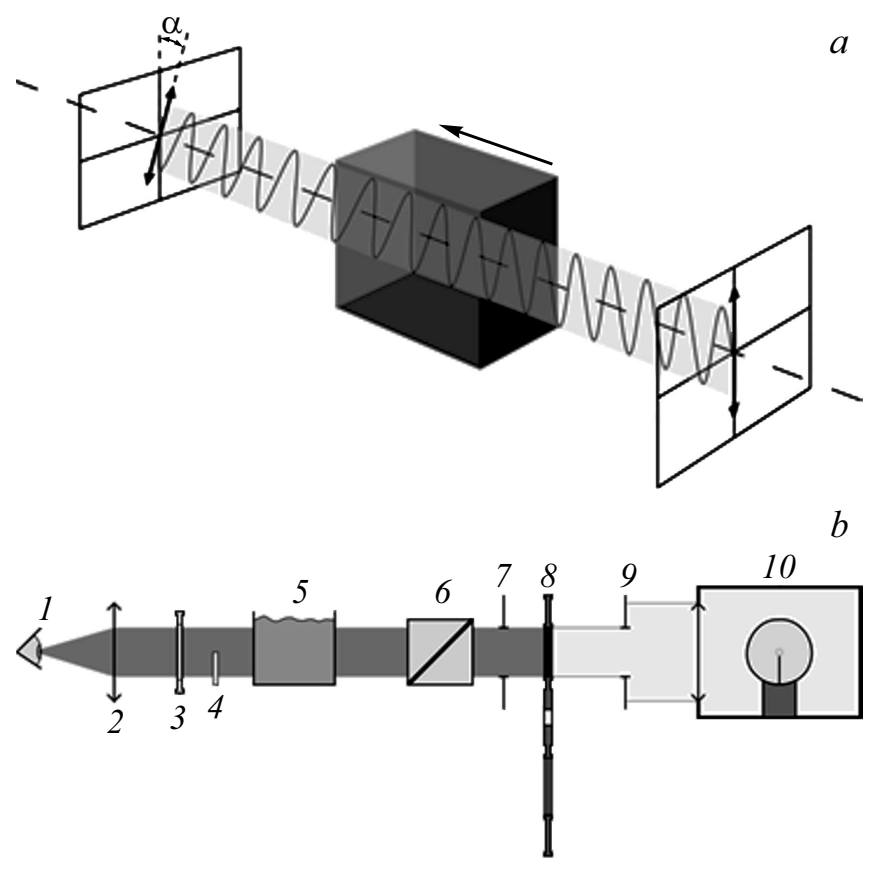

Принцип разворота плоскости поляризации светового луча на угол $\alpha$ при прохождении электромагнитной волны через активную среду $(a)$ и экспериментальная установка для исследования угла вращения плоскости поляризации света в нано- и биоструктурированных материалах $(b) .1$ - глаз исследователя, 2 - окуляр, 3 - вращаемый поляризатор (анализатор), 4 - вращающая поляризацию пластинка, 5 исследуемый раствор в кювете, 6 - поляризационная призма, 7, 9 - диафрагмы, 8 - вращаемая карусель с различными фильтрами, 10 - осветитель, в том числе лазер с длиной волны $633 \mathrm{~nm}$.

лей обеспечивают изменение величины угла вращения плоскости поляризации света в диапазоне от $0.12^{\circ}$ (краситель ENS-291) до 0.2 ${ }^{\circ}$ (краситель ENS-295) и до $0.25^{\circ}$ (краситель ENS-102) при прохождении света через кюветы толщиной $10 \mathrm{~mm}$. Для полноты сравнения необходимо отметить, что для водного раствора сахара с концентрацией $0.05 \mathrm{~g} / \mathrm{cm}^{3}$ было получено значение угла вращения плоскости поляризации света на уровне $0.5^{\circ}$ в аналогичных экспериментальных условиях и при таких же геометрических размерах кварцевой кюветы. Корректирующий аналитический расчет, выполненный для раствора сахара по формуле

$$
\alpha=\alpha_{s p} c l
$$

показал соответствие с экспериментальными данными. Здесь $\alpha_{s p}$ - удельное (specific) вращение плоскости поляризации раствором сахара, $c$ - концентрация, $l-$ длина кюветы с раствором сахара.

Естественно, что винтовая структура ДНК-системы существенно влияет на проявление исследуемого оптического эффекта, что требует дальнейших скрупулезных экспериментов.

Кратко изучен эффект вращения плоскости поляризации света в водных растворах ДНК как один из возможных вариантов оптических исследований фундаментальных свойств материи. Показано, что значения угла вращения плоскости поляризации света для систем с ДНК превышают соответствующие значения, полученные при тестировании растворов сахара и водорастворимых красителей. Подчеркнем, что особое внимание уделено, вопервых, выявлению и подтверждению тенденции общей замены нанообъектов (красителей и др.) на биообъекты (ДНК) при сенсибилизации модельных органических систем, поскольку биообъекты являются нетоксичными и легко возобновляемыми (за счет доступности ресурсов Мирового океана) сенсибилизаторами многих органических материалов. Во-вторых, акцент делается также на сравнение измеряемых параметров с таковыми для классических используемых материалов (растворы сахара), осуществляющих оптический эффект вращения плоскости поляризации света.

Авторы благодарны своим коллегам по совместной работе в рамках международного проекта FP7 Program, Marie Curie Action, Project „BIOMOLEC“ (20122015 гг.), позволившего активно использовать биообъекты (на примере ДНК) для оптических экспериментов.

Данные настоящей работы обсуждались в рамках семинара в ПИЯФ-Курчатовский институт, Гатчина, Россия (11 октября 2017 г). 


\section{Список литературы}

[1] Boutorine A.S., Tokuyama H., Takasugi M., Isobe H., Nakamura E., Helene C. // Angew. Chem. Int. Ed. Engl. 1994. V. 33. P. 2462-2465.

[2] Yamago S., Tokuyama H., Nakamuralr E., Kikuchi K., Kananishl S., Sueki K., Nakahara H., Enomoto S., Ambe F. // Chem. Biol. 1995. V. 2. P. 385-389.

[3] Ikeda A., Hatano T., Kawaguchi M., Suenagab H., Shinkai S. // Chem. Commun. 1999. N 15. P. 1403-1404.

[4] Fritz J., Cooper E.B., Gaudet S., Sorger P.K., Manalis S.R. // PNAS. 2002. V. 99. P. 14142-14146.

[5] Bae A.-H., Hatano T., Sugiyasu K., Kishida T., Takeuchia M., Shinkai S. // Tetrahedron Lett. 2005. V. 46. P. 3169-3173.

[6] Firmino A., Grote J.G., Kajzar F., M'Peko J.-C., Pawlicka A. // J. Appl. Phys. 2011. V. 110. P. 033704 (1-5).

[7] Belikov A.V., Smolyanskaya O.A., Protasov V.A. // Proc. SPIE. 2004. V. 5474. P. $96-102$. DOI: $10.1117 / 12.57837$

[8] Hugel T., Michaelis J., Hetherington C.L., Jardine P.J., Grimes S., Walter J.M., Falk W., Anderson D.L., Bustamante C. // PLoS Biol. 2007. V. 5. N 3. P. e59. https://doi.org/10.1371/journal.pbio.0050059

[9] Olesiak J., Matczyszyn K., Mojzisova H., Zielinski M., Chauvat D., Zyss J. // Mater. Sci.-Pol. 2009. V. 27. P. 813823.

[10] Šmidlehner T., Piantanida I., Pescitelli G. // Beilstein J. Org. Chem. 2018. V. 14. P. 84-105. DOI: $10.3762 /$ bjoc. 14.5

[11] Dancus I., Vlad VII., Petris A., Rau I., Kajzar F., Meghea A., Tane A. // Proc. of SPIE. 2013. V. 8882. P. 88820D (1-5).

[12] Kamanina N.V., Serov S.V., Zubtsova Y.A., Bretonniere Y., Andraud Ch., Baldeck P., Kajzar F. // J. Nanotechnol. Diagnosis Treatment. 2014. V. 2. P. 2-5.

[13] Kamanina N.V., Likhomanova S.V., Zubtcova Yu.A., Kamanin A.A., Pawlicka A. // J. Nanomater. 2016. V. 2016. P. 8989250 (1-9).

[14] Kamanina N.V., Likhomanova S.V., Kamanin A.A. // RAD Conf. Proc. 2017. V. 2. P. 265-268.

[15] Лансберг Г.С. Оптика. 6-е изд. М.: Физматлит, 2003, 848 с.

[16] Каманина Н.В., Зубцова Ю.А., Студёнов В.И., Baldeck P., Bretonniere Y., Andraud Ch. // Жидкие кристаллы и их практическое использование. 2015. Т. 15. № 1. С. 91-94. 